\title{
Teoria da complexidade sob a perspectiva da gestão
}

\author{
Complexity Theory under the management perspective
}

\author{
1 Ernesto José Vieira \\ ${ }^{2}$ Henrique Cordeiro Martins \\ ${ }^{2}$ Carlos Alberto Gonçalves
}

1 Professor do Centro Universitário UNA. ernestoqas@uol.com.br
2 Professor da Universidade FUMEC.

\section{Resumo}

Este trabalho procura verificar se existem elementos típicos da Teoria da Complexidade em empresas que operam em ambiência turbulenta, dinâmica e não linear; e se a visão, missão e objetivos consistem em atratores que evitam que a bifurcação ou ponto de ruptura se instale. Para responder às essas perguntas, tornou-se necessário incluir nesta pesquisa um objetivo geral, além dos específicos. Como suporte, desenvolveu-se um referencial teórico, com um capítulo sobre Teoria da Complexidade e, outro, sobre gerenciamento que, por sua vez, descreve sobre estratégias emergentes. A metodologia foi classificada como qualitativa, por meio de um estudo exploratório. Durante este estudo exploratório, foram entrevistadas dez empresas na área da Grande Belo Horizonte. Essas entrevistas ocorreram em seguimentos industriais, logísticos e de transporte, selecionados em função de suas atividades serem turbulentas, estarem em crescimento e operarem em mercados altamente competitivos. Essas empresas foram entrevistadas por meio de seus dirigentes, que foram selecionados como depoentes pelos funcionários da própria empresa. Os funcionários, por sua vez, indicaram os respectivos dirigentes como os executivos mais adequados para responder às perguntas previamente apresentadas. Registra-se que todos os depoentes responderam às mesmas perguntas, e, posteriormente, a respostas foram comentadas, quando evidenciou-se que os resultados observados validaram as proposições iniciais.

\section{Palavras-chave}

Teoria da Complexidade; atratores; bifurcação.

\begin{abstract}
The objective of the present study seeks to verify if there are typical elements of Complexity Theory in companies which operate in turbulent, dynamic and non-linear environments, and if the vision, mission, and objectives are attractors which can prevent that bifurcation or point of rupture occur. In order to answer these questions, it is necessary to include within the study both general and specific objectives. As a support, a theoretical structure which includes a first chapter about Complex Theory, a second about management that also includes emergent strategy was developed. The methodology were classified as qualitative, by means of exploratory study. During this explanatory study ten companies were interviewed in the Belo Horizonte metropolitan area were interviewed. These interviews were carried out in the segments off industry, logistics and transport. These segments were selected in function of the turbulence of their activities, and the fact that they function in high competitive markets. The interviews were done by means of the selection of the of members of top management, by companies works, to serve as interviewees. This workers referred the respective top managers as the most appropriate to answer previously presented questions. All of the interviewees answered the same questions. The answered were commented upon, in this study, when objective evidence showed that observed results validated the initial prepositions.
\end{abstract}

\section{Keywords}

Complexity theory; attractors; bifurcation.

\section{Como você deve citar?}

VIEIRA, Ernesto José; MARTINS, Henrique Cordeiro; GONÇALVES, Carlos Alberto. Teoria da complexidade sob a perspectiva da gestão. Cadernos UniFOA, Volta Redonda, n. 28, p. 51-66, ago. 2015. 


\section{INTRODUÇÃO}

Segundo Morgan (2002), as teorias da administração incorporaram os conhecimentos da física newtoniana, originando modelos de organização vistos como máquinas, adequados ao ambiente estável das primeiras décadas do século XX. Entre as décadas de 1930 e 1960, incorporaram-se os conhecimentos da Sociologia e da Biologia, originando os chamados modelos orgânicos, que consideram a influência do ambiente e a necessidade de flexibilidade interna da organização, para se adaptar e evoluir em ambientes mutáveis. A partir das décadas de 1960 e 1970, o crescimento dos mercados aumentou a competição entre as organizações, que têm enfrentado o desafio de tentar acompanhar a dinâmica de seus ambientes. (EISENHARDT; SCHOONHOVEN, 1990).

Mariotto (2003) advoga que, sob a pressão de uma competição intensificada, as organizações têm, cada vez mais, buscado flexibilidade, inovação, habilidades múltiplas, descentralização e novos usos para a tecnologia de informação e comunicação, assumindo frequentemente novos formatos. Uma complexidade crescente caracteriza os ambientes internos e externos, enfrentados pelas organizações. Essas necessidades criam uma combinação de complexidades que exercem grande pressão sobre as empresas, sendo sentidas especialmente na área de formação das estratégias.

A maneira tradicional de desenvolver estratégia como um processo periódico e formal de planejamento já não é suficiente para lidar com a nova situação. 0 que a ciência contemporânea vem demonstrando, por meio das teorias da complexidade, é que tanto o equilíbrio quanto a previsibilidade são exceção e não regra. (MATOS et al., 2007).

De acordo com Thietart e Forgues (1995), a previsibilidade é artificial e, a repetitividade, perigosa. Em se tratando de um sistema complexo, não é possível prever o comportamento de longo prazo, independentemente da capacidade do gerente e de suas ações. Quando a organização está sob o domínio da complexidade, uma previsão somente pode ser feita em prazos curtos, porque, em prazos longos, mesmo pequenas variações podem gerar um grande impacto no resultado organizacional.

Assim, esta pesquisa procura solução para os seguintes problemas: existem elementos típicos da Teoria da Complexidade na gestão de organizações que operam em ambiência turbulenta, dinâmica e não linear? A visão, missão e objetivos consistem atratores que evitam que a bifurcação ou que ponto de ruptura se instale? Para responder às perguntas acima, necessita-se incluir nesta pesquisa oobjetivo geral de analisar a teoria da complexidade sob a perspectiva da gestão. Tornou-se necessário, ainda, incluir também o objetivo específico de analisar os conceitos da Teoria da complexidade e gerenciamento em empresas dinâmicas e não linear. Para suporte a esses objetivos, desenvolveu-se um referencial teórico. 2 Revisão de Literatura

\subsection{Conceitos}

\subsubsection{Teoria da Complexidade}

Giovannini e Kruglianskas (2004) advogam que nenhum problema ou comportamento pode ser compreendido isoladamente, eque é necessário levar em consideração as dinâmicas em operação no sistema global e que, portanto, um mundo sistêmico não pode ser entendido pelo exame exclusivo de acontecimentos ou indivíduos isolados (WHEATLEY, 2006).

Prigogine (1996) salienta que, o reconhecimento do papel das flutuações e da instabilidade no mundo moderno revela que as escolhas múltiplas se adaptam melhor às previsibilidades limitadas de curto prazo. Fazendo menção à Física tradicional, o autor relembra que, para essa ciência, desde que 
fossem dadas condições iniciais apropriadas, estaria garantida a previsibilidade do futuro. Assistimos ao surgimento de uma ciência que não mais se limita a situações simplificadas, idealizadas, mas que nos põe diante da complexidade do mundo real.

A visão de Newton, segundo Freitas (2005), gera nas pessoas um padrão de pensamento que tende à simplificação. Essa visão simplista do mundo está sendo substituída por outra, essencialmente complexa e paradoxal. Comparando o pensamento mecanicista com o pensamento sistêmico, a ciência cartesiana acreditava que, em qualquer sistema complexo, o comportamento do todo podia ser analisado por meio de suas partes. Mas a ciência sistêmica mostra que as partes só podem ser entendidas dentro do contexto total.

Segundo Guo et al. (2009), os modelos organizacionais que, no passado, foram utilizados amplamente, não são eficazes em sistemas complexos, imprevisíveis e irregulares.

A ciência contemporânea, segundo Matos e Almeida (2007), vem demonstrando que a teoria da complexidade é mais regra do que exceção. Esse entendimento permite uma melhor compreensão das dinâmicas organizacionais nos contextos de forte turbulência, como também permite que as organizações se tornem capazes, não apenas de conviver com a turbulência, mas de tirar partido dela, para evoluir a partir de sistemas complexos.

Os sistemas complexos adaptativos têm seu comportamento estudado pela teoria da complexidade, cuja principal característica é responder ou mudar a cada nova informação que chega do ambiente. Um sistema complexo adaptativo é formado por vários componentes de agentes adaptativos que interagem entre si, de acordo com um conjunto de normas, isto é, seu comportamento se modifica à medida que evolui e interage com o ambiente (FREITAS, 2005).

\subsubsection{Complexidade de sistemas organizacionais}

Segundo Giovannini e Kruglianskas (2004), os sistemas organizacionais que sobrevivem e evoluem são mais compreendidos se considerarmos que estão sujeitos aos aspectos da complexidade, abaixo relacionados:

a. estão à mercê da Dependência Sensitiva às Condições Iniciais (DSCl) e, portanto, sujeitos à incerteza, a partir de um determinado número de ciclos.

b. operam em estabilidade dinâmica em torno de atratores, que podem mudar de posição em função da capacidade adaptativa.

Radosavljević e Horner (2002) exemplificam que a execução de projetos é frequentemente turbulenta, em função do número de variáveis envolvidas, trabalho intenso, e a ocorrência de eventos imprevisíveis.

\subsubsection{Comportamento não linear}

O comportamento não linear, característico dos sistemas complexos, é aquele cuja resposta a um determinado estímulo não é, necessariamente, proporcional à intensidade desse estímulo. 0 efeito feedback quebra a linearidade de tal forma que a causa age sobre o efeito e o efeito age sobre a causa, tornando-se causador ao retroagir sobre a causa. Nos sistemas complexos, não sendo possível construir o sistema, como um todo, por meio da soma de suas partes. Esses sistemas possuem estrutura não linear, em virtude de os seus componentes e o ambiente onde estão inseridos estarem interligados por 
processos de feedbacks recursivos, fazendo com que, ao longo do seu funcionamento, pequenas perturbações sejam ampliadas, quebrando o vínculo entre entrada e a saída subsequentes (FREITAS, 2005).

Segundo Matos e Almeida (2007), as dificuldades de as empresas conviverem em sistemas complexos se devem a dois fatores fundamentais: o primeiro fator é que as organizações buscam a estabilidade, procurando se adaptar às mudanças ocorridas no ambiente externo - princípio do retorno ao equilíbrio; o segundo é que as organizações acreditam que as decisões e as ações conduzem aos resultados previstos - princípio da linearidade da causa e efeito. 0 conceito de feedback, segundo Giovannini e Kruglianskas (2004), permite representar essas interrelações e visualizar a possibilidade de sistemas autorregulados por meio de circuitos de retroalimentação.

\subsubsection{Atrator em organizações}

Entende-se, por atrator, um conjunto invariante, para o qual órbitas próximas convergem depois de um tempo suficientemente longo, isto é, valores para os quais tendem os valores resultantes de um sistema dinâmico não linear, após certo número de ciclos. 0 valor do atrator nunca é alcançado, pois este, dependendo sensitivamente das condições iniciais do sistema. Isso significa que, quer por imprecisões inerentes ao sistema, necessariamente, quer por ruído experimental, o valor exato do atrator não é calculável nem previsível com precisão absoluta (GIOVANNINI; KRUGLIANSKAS, 2004).

Bertalanffy (2008) considera outra forma de organização, com os conceitos de propósito ou objetivo, que podem funcionar como um atrator em empresas complexas. Todo sistema tem um ou alguns propósitos específicos dentro de sistemas maiores. As partes ou elementos do sistema, bem como os relacionamentos entre essas partes, definem uma estrutura que visa sempre a um propósito ou finalidade a alcançar.

\subsubsection{Redundância}

Wheatley (2000) sustenta que as organizações podem se valer da redundância, da imprecisão, de densas teias de relacionamentos e de uma incansável cadeia de tentativas e erros para descobrir quais opções funcionam. A simultaneidade reduz os efeitos de qualquer erro, desde que os elementos não estejam ligados sequencialmente. As colônias de bactérias localizam seu alimento, enviando batedores aleatórios, cada um com um número grande de bactérias.

\subsection{Gerenciamento}

\subsubsection{Subconsciente, razão e o pensamento sistêmico}

Thietart e Forgues (1995) sustentam que o gerenciamento contém elementos de racionalidade e ordem junto com intuição, informalidade e desordem. Senge (2008) advoga que é através do subconsciente que todos nós lidamos com a complexidade, acrescentando que o subconsciente não tem vontade própria, não gera seus próprios objetivos nem determina seu foco, sendo sujeito à orientação e ao condicionamento. Aquilo a que prestamos atenção assume importância especial para o subconsciente. Devemos nos direcionar a um foco, concentrar no resultado desejado e não no processo ou nos meios que consideramos necessários para alcançar o resultado.

O ensaio mental de efeitos complexos, segundo Brown e Eisenhardt (1998), tornou-se um treinamento psicológico de rotina para diversos artistas profissionais. Esses autores consideram, como o ensaio mais importante para o desenvolvimento da comunicação com o subconsciente, a verdadeira preocupação com o resultado desejado, o sentimento profundo de ser essa a meta à qual se aspira. 
Senge (2008) complementa que líderes experientes se apoiam muito na sua intuição e não tentam resolver problemas complexos inteiramente com base na racionalidade, conseguindo essa integração entre razão e intuição naturalmente e não precisando fazer uma escolha.

Senge (2008) advoga, ainda, que o pensamento sistêmico pode ser a chave para a integração de razão e intuição. A intuição escapa à compreensão do pensamento linear, com sua ênfase exclusiva em causa e efeito, próximos no tempo e no espaço. Frequentemente, gerentes experientes têm ótimas intuições que não conseguem explicar, sobre sistemas complexos.

Parikh, Neubauer e Lang (2003) reiteram que a chave para o capital intelectual é a intuição. Segundo esses autores, quase todos nós fomos moldados por organizações burocráticas, dominadas por uma orientação com base no comando e no controle. Os líderes e administradores devem usar e desenvolver sua capacidade intuitiva e criar um ambiente em que a intuição seja valorizada e recompensada, para a eficácia da organização.

Mintzberg (2004) registra que toda a natureza da formação estratégica, dinâmica, irregular e descontínua interativa, com ênfase em aprendizado e síntese, força os gerentes a preferir a intuição. Provavelmente, esse seja o motivo de as técnicas analíticas de planejamento não serem tão assertivas. As pessoas resistem às estruturas em etapas porque sua tendência é holística, no sentido de que todas as etapas são consideradas simultaneamente. 0 custo de investimento da intuição é mais alto, uma vez que não se pode ser intuitivo, a menos que se tenha conhecimento íntimo do assunto em questão, o que, às vezes, demanda anos.

Essas respectivas vantagens e desvantagens entre intuição e análise se tornaram mais claras em um experimento conduzido por Peters et al. (1974), quando, concluiu que a abordagem analítica à resolução de problemas conduz mais vezes a uma resposta precisa, mas sua distribuição de erros é bem mais ampla. A intuição, em comparação, é precisa com menos frequência, porém mais consistentemente próxima. Para a intuição, uma resposta bizarra parece errada e é reconsiderada. Por meio de análise, os erros têm mais probabilidades de passar despercebidos.

Segundo Mintzberg (2004), as decisões disponíveis rapidamente, a partir da intuição, devem, às vezes, ser verificadas quanto à análise formal, enquanto as produzidas por análise meticulosa devem, em geral, ser confirmadas intuitivamente quanto à validade aparente. A empresa deve conciliar análise e intuição, assim como outros processos, na formação de sua estratégia.

Mintzberg (2004) sustenta que os administradores precisam ser capazes de analisar os problemas sistematicamente, com auxílio de ferramentas analíticas. Também precisam ser capazes de responder às situações rapidamente, em função da velocidade das mudanças ambientais, habilidade que requer o cultivo da intuição, uma habilidade que requer o cultivo da intuição e do julgamento, ao longo de muitos anos de experiência e treinamento. 0 administrador eficaz não se dá ao luxo de escoIher entre abordagens analíticas e intuitivas de problemas. A análise, portanto, passa a ser um diálogo contínuo, em vez de um serviço todo feito de uma vez. Peters et al. (1974), baseados em experimentos que realizaram, registram que é possível utilizar a intuição quando as consequências do erro não são muito graves. 0 pensamento analítico é, portanto, ligado à certeza e deveria produzir desempenho caracterizado pela predominância de respostas corretas e precisas, mas acompanhado ocasionalmente por respostas com erros graves. Em consequência das velocidades atuais das mudanças, consciente ou inconscientemente, precisamos recorrer à intuição. 0 modo de pensar convencional, analítico, já não é adequado para permitir que atuemos eficazmente no cenário incerto, pois, muitas vezes, não temos tempo para fazer uma reunião a cada vez que uma mudança provoca modificações nos planos. Depois de visualizadas as metas, nos movemos naturalmente à escolha do caminho mais direto para 
atingi-las. 0 visionamento intuitivo facilita a liberação da criatividade inata da pessoa, livre das limitações impostas pelo pensamento linear, racional ou analítico, ou por preconceitos.

\subsubsection{Estratégias emergentes}

O termo estratégia emergente, segundo Mariotto (2003), foi introduzido na década de 1970, por Henry Mintzberg, e significa uma estratégia não planejada, no sentido de uma linha de ação que só é percebida como estratégica, pela organização, à medida que ela vai se desenrolando ou até mesmo depois que já aconteceu. A estratégia emergente foi definida como um padrão de ação, seguido pela ausência de um plano ou em desacordo com um plano existente. Estratégia deliberada, em contrapartida, foi definida como um padrão de ação seguido de acordo com um plano. Assim como o pensamento complexo e estratégia emergente é mais apropriada para o ambiente complexo e não linear.

Mintzberg et al. (2000) postulam que uma estratégia emergente seria aquela que surge da organização em resposta a uma oportunidade do ambiente. Ela vem da dificuldade de se prever com precisão o comportamento organizacional e as interações da organização com o ambiente. As estratégias deliberadas e emergentes, segundo Mintzberg e Waters (1985), devem ser entendidas como dois extremos ao longo dos quais o mundo real se encontra. Esses autores definem estratégias como correntes de ações, não de decisões. 0 que podemos esperar são tendências nas direções de estratégias deliberadas ou emergentes, e não formas perfeitas de ambas.

Mariotto (2003) propõe que as estratégias emergentes, não definidas por meio formais, são mais apropriadas para as empresas que operam em ambientes complexos, turbulentos ou de grande incerteza. Porém, reconhece a importância de um planejamento formal, sugerindo a utilização dos dois tipos de estratégias. Esse autor apresenta a estratégia emergente como fenômeno cognitivo, explicando que o comportamento humano é tanto um processo de descobrir objetivos como o de agir a partir deles. Valores mudam e são desenvolvidos com a experiência.

Segundo Mintzberg et al. (2000), todas as estratégias do mundo real precisam combinar a estratégia deliberada com a estratégia emergente. Os estrategistas eficazes as misturam de maneira que reflitam as condições existentes, especialmente, capacidade para prever e, também, a necessidade de reagir a eventos imprevistos, isto é, o mundo real exige pensar no futuro ealguma adaptação durante o percurso. Reconhece a capacidade e necessidade de a organização experimentar diversas opções ou formas de trabalho. A estratégia também necessita ser mudada, com a mudança da ambiência.

\subsubsection{Necessidade da mudança de estratégia}

As técnicas tradicionais de administração, segundo Anselmo (2005), são válidas para as questões fechadas e de curto prazo, mas falham ao lidar com as questões abertas e de longo prazo, tipicamente as ligadas às mudanças imprevisíveis dos ambientes complexos. A abordagem tradicional da estratégia, baseada na escolha de um mercado atrativo, na definição de um posicionamento competitivo único e na definição das ações para alcançar essa posição, geralmente, falha frente a setores em rápidas e imprevisíveis mudanças. O principal desafio da estratégia é a gestão das mudanças e como fazê-la. O sucesso é medido pela habilidade de sobreviver, reinventar a empresa, constantemente, ao longo do tempo. $O$ indutor chave do desempenho superior é a habilidade de mudar.

Anselmo (2005) defende também que as organizações devem assumir uma condição de mudança contínua, baseada em três tópicos centrais: 
- Estado intermediário de organização, no qual a empresa assume um equilíbrio dinâmico, permitindo um comportamento adaptativo e complexo, gerando a capacidade de autoorganização. Nesse ponto, a estratégia baseia-se na capacidade de improvisação e na coadaptação.

- Foco no presente, com atenção no passado como forma de aprendizado e possibilidades no futuro.

- Definição de regras simples a partir das experiências dos gerentes em outras empresas, que surgem de um processo emergente e não estruturado.

\subsubsection{A mudança dentro da abordagem da complexidade}

Bauer (2008), Giovannini e Kruglianskas (2004) sustentam que a estratégia da mudança, no limiar da turbulência, é algo resultante da capacidade que a empresa tem de se organizar para mudar constantemente, abrindo espaço para a emergência. Ao contrário da tradicional, essa estratégia é imprevisível e eficaz em curto prazo, sendo permitido entrar em mercados errados, retornando ao certo; ou seja, implica duplicidade, inadequação, erro e, às vezes, o acréscimo da aleatoriedade.

Essa constante transformação, dentro da abordagem da complexidade, para Giovannini e Kruglianskas (2004), é o modo como os sistemas geram novas alternativas de sobrevivência. Não são necessariamente respostas às mudanças no ambiente. As alternativas são geradas espontaneamente e colocadas à prova. Aquelas bem-sucedidas continuam sua evolução, gerando novas alternativas. Assim, a transformação organizacional não é um processo de reação às solicitações do mercado, mas uma forma eficaz de busca da sobrevivência por intermédio de uma incessante criatividade e inovação, impossibilitando, portanto, a certeza e previsibilidade.

Essa ilusão de certeza ou de previsibilidade probabilística, segundo esses autores, pode levar a decisões e ações cujos resultados estarão longe dos objetivos da organização, sendo um desperdício de esforço e de recursos. 0 conceito de estabilidade na mudança está presente na ideia de que a organização que consegue mudar e sobreviver é aquela que adota a transformação como um processo contínuo e interminável, inerente à própria organização (GIOVANNINI E KRUGLIANSKAS, 2004).

\subsubsection{Folgas organizacionais, variedade e redundância}

Giovannini e Kruglianskas (2004) defendem que, no mundo real, as organizações sempre possuem folgas como: estoques, que poderiam ser um pouco menores; salários, que poderiam ser reduzidos sem perder empregados; preços, que poderiam ser um pouco maiores, sem perder mercado e outros.

Devemos buscar algum grau de compromisso entre variedade (diversidade) e redundância (repetição). Os sistemas com capacidade de sobreviver e evoluir geram processos redundantes, sendo que a redundância é um afastamento previsível da aleatoriedade (CKEIK, 2008; BAUER, 2008, GIOVANNINI E KRUGLIANSKAS 2004).

\subsubsection{Utilização da missão, valores, culturas como atrator nas organizações}

Há uma tendência de os sistemas complexos serem atraídos por certo padrão de comportamento, como um atrator estranho (BAUER, 2008). De acordo com Hitt et al. (2000), a cultura organizacional está relacionada ao conjunto de ideologias, símbolos e valores que são compartilhados por toda organização, sendo capaz de influenciar no comportamento da organização como um todo. Assim, os gerentes podem utilizar a missão, cultura e valores da organização como atrator. 
Freitas (2005) defende que a ideia do atrator estranho é importante porque mantém o comportamento instável da organização, mas dentro de limites, um estado essencial para a inovação e, portanto, importante para a competitividade da organização. 0 controle gerencial exercido por meio de valores e propósitos é sutil e poderoso, capaz de governar o comportamento da organização.

Daft e Lengel (2001) também sugerem a adoção da visão ou missão como atrator, para servir de supervisão ou controle gerencial, como uma nova forma de liderar e de desenhar organizações, tornando os gestores capazes de delegar a autoridade e de confiar na capacidade de seus funcionários encontrarem soluções para os problemas locais, proporcionando espaço para o comportamento criativo dos indivíduos e equipes. Esses autores lembram também que o princípio de autorreferência baseia-se na ideia de que as pessoas não se desviam da missão global da sua organização, caso se identifiquem com a mesma.

Os gerentes, segundo Morgan (2000), devem adotar controles de natureza diversa e restritos, minimamente, indispensável. Os controles se farão basicamente em termos de resultados coletivos e setoriais, com o mínimo possível de procedimentos. Eles devem concentrar-se na facilitação, articulação e gerenciamento dos limites, criando condições propícias para permitir que o sistema descubra sua própria forma. Esse princípio ajuda a preservar a capacidade de auto-organização, que a mentalidade burocrática geralmente destrói. Entretanto, a ênfase do controle deverá ser colocada nos valores organizacionais críticos. Esses valores são os mínimos indispensáveis para garantir a coesão, a sobrevivência coletiva e a adesão ao sistema da organização.

Para Nonaka (1997), os estados de desordem são intrínsecos às organizações, e as instabilidades, que os gerentes, muitas vezes, combatem, contêm importantes oportunidades criativas, que podem gerar aprendizado, transcendendo as práticas estabelecidas de pensamento estratégico.

\subsubsection{As organizações como sistemas não lineares}

A aplicação dos conceitos de complexidade nas organizações pressupõe o entendimento dessas organizações como sistemas não lineares complexos, ou seja, sistemas onde ocorre o fenômeno de realimentação (feedback) positiva, levando a uma dinâmica cujos resultados não são previsíveis, mas onde existe uma ordem emergente (ANSELMO, 2005).

Anselmo (2005) registra que, para sobreviver e crescer em ambientes turbulentos, as organizações devem buscar equilibrar seus processos gerenciais de realimentação negativa e positiva, apresentando também os seguintes princípios:

- natureza descentralizada, que remeta às decisões operacionais de curto prazo para a linha de frente.

- sistema decisório estratégico, que defina linhas gerais de cima para baixo, mas que incentive as escolhas de baixo para cima, propiciando o processo de auto-organização.

- controles mais amplos e gerais, que incentivem o autocontrole das pessoas e equipes.

- condições para a emergência da criatividade e inovação. 


\subsubsection{Modelo de gestão não linear}

Eisenhardt e Brown (1999) apresentam um processo, que resulta em uma estrutura corporativa adaptável, para enfrentar mercados turbulentos e imprevisíveis. Esse processo, denominado patching ou remendar, consiste em rearranjar rotineiramente os negócios às mudanças e oportunidades de mercado.

Enfatizando auto-organização, Morgan (2002) advoga que os administradores não devem impor demasiado controle sobre o processo de mudança, mas ser capazes de definir especificações mínimas que permitam a auto-organização do sistema. Tais especificações mínimas se configuram como os atratores.

A chave para o processo de mudança, segundo Morgan (2002), reside na criação de novos contextos que quebrem os padrões de atração em favor de novos padrões. Os modelos tradicionais de gestão fundamentam sua ação no controle das tarefas e ou dos resultados. Esse controle, na verdade, age como defesa do sistema contra o desconhecido, mas, por outro lado, inibe o seu desenvolvimento natural e potencial. Dentro dos conceitos da complexidade, a resposta a esse desafio está na criação do atrator organizacional, que consiste em poucas normas e valores, incorporados nas pessoas da organização, proporcionando-lhes alto grau de liberdade e criatividade.

\subsubsection{Improvisação}

Segundo Bauer (2008), a improvisação caracteriza-se por duas propriedades-chave: a primeira é que os participantes comunicam-se intensamente uns com os outros, em tempo real; a segunda é que eles se concentram, deliberadamente, no que está acontecendo naquele momento, no grupo. A improvisação relaciona-se à ampla comunicação em tempo real no contexto administrativo, o que permite aos administradores ajustar-se contínua e criativamente à mudança.

Bauer (2008) postula ainda que as empresas que improvisam têm as seguintes características comuns:

- cultura adaptativa: a mudança é a norma, e não a exceção.

- semiestruturas: os administradores baseiam-se em pontos que jamais são violados, como os prazos, principais resultados.

- comunicação em tempo real: comunicação ao longo de todos os seus segmentos.

\subsubsection{Deveres essenciais para os gerentes}

Nessa perspectiva, os gerentes têm alguns deveres que são essenciais, como:

- Gerenciar a transição: conduzir os funcionários da era da industrialização para a era da informação, do mundo de Newton para o mundo da complexidade.

- Construção de resiliência: com a velocidade, das mudanças segundo Tetenbaum (1998), a resistência mental e física dos trabalhadores tem diminuído. A Teoria da Complexidade enfatiza a importância da habilidade de se adaptar e absorver mais mudanças. Os gerentes devem ajustar sua expectativa e ajudar os trabalhadores, por meio de treinamento, a aumentar sua resiliência. 
- Desestabilizar o sistema: os administradores precisam manter a tensão em um ponto que gere uma imaginação dinâmica, sem exceder a habilidade das pessoas de controlar o estresse provocado (TETENBAUM, 1998).

- Gerenciamento de ordem e desordem, do futuro e do presente: esse paradoxo, que realmente consiste na regularidade e irregularidade, simplicidade e complexidade, previsibilidade e imprevisibilidade, demanda uma grande agilidade por parte dos gerentes. É necessário encontrar um ponto entre estes dois extremos (TETENBAUM, 1998).

- Criar e manter uma organização de aprendizado: o maior papel dos gerentes em organizações dinâmicas e complexas, segundo Tetenbaum (1998), é criar os meios para que todos possam ser envolvidos em um aprendizado contínuo.

- Desenvolver novas perspectivas sobre o que é controle: segundo Freitas (2005), o controle pode ser exercido agindo sobre os limites e não sobre o próprio processo ou sobre o resultado, o que pode inibir a inovação.

- Criar senso de crise e correr riscos: Nonaka e Takeuchi (1997) postulam que as organizações onde as questões estratégicas evoluem com êxito são aquelas em que as pessoas são encorajadas a assumir desafios, riscos e promover mudanças.

- Aperfeiçoar as técnicas de aprendizagem organizacional: as orientações estratégicas criativas e inovadoras, segundo Freitas (2005), emergem de atividades de aprendizagem, mas essa aprendizagem é denominada complexa, porque não é simplesmente a absorção de conteúdos existentes de conhecimentos, de conjuntos de técnicas ou de receitas e prescrições existentes. Essa aprendizagem complexa implica na alteração dos modelos mentais existentes, enfatizando como se aprende em conjunto e como se interage com os outros.

- Incentivar o pensamento sistêmico: a vida organizacional, segundo Morgan (2000), é um fenômeno complexo, instável e imprevisível, e, portanto, deve ser tratado sob essa perspectiva. Esse autor destaca que, muitos dos problemas com os quais nos deparamos originam-se do fato de que a simplicidade do nosso pensamento não é compatível com a complexidade e a sofisticação das realidades com que temos de lidar. A organização, segundo Thietart e Forgues (1995), é apresentada como um sistema aberto, dinâmico e não linear, sujeito a forças internas e externas.

- Administração de conflitos, ordem e desordem: Tetenbaum (1998) advoga que, se as ideias inovadoras são realmente o primeiro objetivo, então a cultura deve tolerar o conflito. Pessoas desafiadoras que se testam publicamente, por meio de debates.

\subsubsection{Eficiência na abordagem da complexidade}

Segundo Giovannini e Kruglianskas (2004), na abordagem da complexidade, a busca da eficiência nas organizações frequentemente compromete a capacidade de criação de alternativas, canalizando os recursos em forma de especialização. Em um ambiente em constante mutação, qualquer tipo de especialização pode ser uma ameaça à sobrevivência. A organização se torna extremamente apta para explorar um determinado ambiente, e, de outro lado, completamente incapaz de sobreviver a uma mudança. Para sobreviver, o sistema não precisa encontrar a melhor alternativa possível, basta que funcione. Ao contrário do que se tornou aceito, o processo que garante a evolução das organizações e o dos seres vivos não é o da sobrevivência do mais forte, mas do mais adaptado. Encontrar a melhor alternativa é impossível, dentro da abordagem da complexidade, em função da incerteza provocada 
pela Dependência Sensitiva às Condições Iniciais (DSCl). A procura por eficiência a todo o custo pode ser uma opção perigosa.

\section{METODOLOGIA}

A pesquisa foi realizada por meio de um estudo exploratório, para identificar se existem elementos típicos da Teoria da Complexidade na gestão de organizações que operam em ambiência turbulenta, dinâmica e não linear, e se a visão, missão e objetivos consistem atratores que evitam que a bifurcação ou que ponto de ruptura se instale. Durante este estudo exploratório, foram entrevistadas dez empresas.

Essas entrevistas ocorreram em segmentos industriais, logísticos e de transporte, selecionados em função de suas atividades serem turbulentas, estarem em crescimento, e operarem em mercados altamente competitivos. As respectivas razões sociais dessas empresas, abaixo relacionadas, foram substituídas por siglas, para manter o sigilo, atendendo à solicitação de alguns depoentes.

1-AC: beneficiamento e comercialização de produtos siderúrgicos, 56 funcionários.

2 DI : fábrica de tintas, 50 funcionários.

3-AR: estudos e planejamento logísticos em transportes industriais. Empresa em fase de crescimento, 100 funcionários. Bases em Contagem, São Paulo, Belém e Macapá.

4-VN: transporte de passageiros urbano e metropolitano, fretamentos, especiais, transporte escolar, 800 funcionários.

5-KB: usinagem e caldeiraria de peças para siderurgia e mineração, 250 funcionários.

7-EG: projetos e fabricação de máquinas hidráulicas, 50 funcionários.

8-TI: comercialização e industrialização de tubos de aço, 48 funcionários

9-EL: projeto e fabricação de equipamentos eletromecânicos para controle e automação industrial e produtos para condução de energia elétrica. Empresa em fase de crescimento, com 75 funcionários.

10-PE: fabricação de perfiz e estruturas, 250 funcionários.

As empresas foram entrevistadas por meio de seus dirigentes que, por sua vez, foram selecionados como depoentes pela indicação de funcionários da própria empresa. Esses funcionários indicaram os respectivos dirigentes como os executivos mais adequados para responder às perguntas previamente apresentadas, descritas no item análise dos dados.

As perguntas utilizadas estão seguidas de análise. Ressaltamos algumas respostas em função de sua importância para este trabalho. As respostas, por sua vez, foram comentadas e relacionadas à fundamentação teórica. 


\section{ANÁLISES DE DADOS}

Neste item, são apresentados e analisados os resultados da pesquisa. A análise consiste na comparação das respostas dos depoentes com o referencial teórico, verificando, assim, o ajustamento ou não dos resultados obtidos frente às proposições teóricas deste estudo.

Apresentação e análise de cada pergunta elaboradas, seguidas dos comentários:

Pergunta 1: Como manter a empresa em equilíbrio dinâmico, crescendo, tendo rentabilidade superior à média, gerando valor?

Enfatiza-se que, a experiência amplamente citada, pode ser relacionada à utilização da intuição, elemento importante na gestão de empresas complexas e não lineares (MINTZBERG, 2004; THIETART; FORGUES, 1995; SENGE, 2008; PARIKH; NEUBAUER; LANG, 2003; MINTZBERG, 2004; PETER et al., 1974).

Comentários: Um depoente considera que pode manter o crescimento em equilíbrio dinâmico, por meio de treinamento dos colaboradores, o que coincide com outro elemento importante de empresas complexas e não lineares, pois os funcionários devem ser treinados para resolver problemas que estão fora da rotina (SENGE, 2008; NONAKA; TAKEUCHI, 1997).

Outro depoente advoga que existe um fator que deve ser considerado que é a falta de motivação ou a falta de sonho, seja do empresário, seja das pessoas que compõem a administração da empresa, ou seja, da própria pessoa física. Se você deixa de sonhar, a possibilidade de você ter insucesso e fazer com que aquela parte econômica da empresa deixe de existir é muito grande (Sic).

Comentário: Essa afirmação de sonho, como fator importante para o sucesso, coincide com o pensamento de Frankl (1989), que postula que tanto as pessoas como as empresas precisam ter uma visão de futuro, ou seja, estabelecimento de objetivos, para se motivarem, independentemente do estado em que se encontram, muito bom ou muito ruim. Essa afirmação sobre o sonho motivou a pergunta sobre o possível compartilhamento desses sonhos da direção com os funcionários.

PE 2-a: Esta direção já teve a ideia de dividir estes sonhos, visões e objetivos com a empresa?

Sim, na realidade você não pode ter sonhos distantes porque você vive num mundo moderno e muito dinâmico. Às vezes, posso pensar que, fazendo doce, vou ficar economicamente muito bem. Mas, quando encontro com uma mídia dizendo que doce engorda, isso torna, assim, o negocio inviável. Portanto, temos que ter flexibilidade para colocar outro sonho em ação (Sic).

Comentário: A tentativa de verificar se o pensamento de Frankl (1989) coincidia com o depoente motivou a pergunta 2-b.

PE 2-b: Esta direção acredita que esse sonho possa ser compartilhado, unindo pessoas para uma mesma direção ou objetivo, dentro de uma mesma situação muito turbulenta?

Sim, você tem que mostrar para as pessoas que todos estão num mesmo barco e, se não remarmos na mesma direção, não chegaremos a lugar nenhum (Sic).

Comentários; As abordagens 2-a e 2-b evidenciam a possibilidade de utilizar missão, valores, culturas como atratores estranhos nas organizações (BAUER, 2008; DRAFT; LENGEL, 2001; MORGAN, 2000) 
Ressalta-se a ampla utilização de experiência ou intuição, além de treinamentos para os colaboradores, assim como o sonho entendido como perspectiva de futuro (TETENBAUM, 1998; SENGE, 2008; NONAKA; TAKEUCHI, 1997; THIETART; FORGUES, 1995; SENGE, 2008; BROWN; EISENHARDT, 1998; PARIKH; NEUBAUER; LANG, 2003; MINTZBERG, 2004; PETERS et al.,1974; BAUER, 2008).

PE 2-a: Esta direção já teve a ideia de dividir estes sonhos, visões e objetivos com a empresa?

Sim, na realidade você não pode ter sonhos distantes porque você vive num mundo moderno e muito dinâmico. Às vezes, posso pensar que, fazendo doce, vou ficar economicamente muito bem. Mas, quando encontro com uma mídia dizendo que doce engorda, isso torna, assim, o negocio inviável. Portanto, temos que ter flexibilidade para colocar outro sonho em ação (Sic). A tentativa de verificar se o pensamento de Frankl (1989) coincidia com o depoente, motivou pergunta 2-b.

PE 2-b: Esta direção acredita que esse sonho possa ser compartilhado, unindo pessoas para uma mesma direção ou objetivo, dentro de uma mesma situação muito turbulenta?

Sim, você tem que mostrar para as pessoas que todos estão num mesmo barco e, se não remarmos na mesma direção, não chegaremos a lugar nenhum (Sic).

As abordagens 2-a e 2-b evidenciam a possibilidade de utilizar missão, valores, culturas como atratores estranhos nas organizações (BAUER, 2008; DRAFT; LENGEL, 2001; MORGAN, 2000)

Ressalta-se a ampla utilização de experiência ou intuição além de treinamentos para os colaboradores, assim como o sonho entendido como perspectiva de futuro (TETENBAUM, 1998; SENGE, 2008; NONAKA; TAKEUCHI, 1997; THIETART; FORGUES, 1995; SENGE, 2008; BROWN; EISENHARDT, 1998; PARIKH; NEUBAUER; LANG, 2003; MINTZBERG, 2004; PETERS et al.,1974; BAUER, 2008).

Pergunta 3: A estratégia da empresa é mudada continuamente com a finalidade de manter o equilíbrio dinâmico e evitar a bifurcação ou turbulência máxima?

Salienta-se que a empresa AC, por meio de seu dirigente, não acredita na necessidade de haver mudança constante, acrescentando que, se está trilhando um caminho e se encontra uma dificuldade, nesse momento é necessário mudar a estratégia, mas obrigatoriamente não se tem que mudar antes de ver o resultado. 0 que está acontecendo é que o pessoal está mudando para ter um resultado meIhor, sem saber se o resultado anterior está satisfatório (Sic). Está havendo um atropelo de metas (Sic).

Esse comentário coincide com a eficiência em sistemas complexos e não lineares, uma vez que, para sobreviver, o sistema não precisa encontrar a melhor alternativa possível, basta que funcione (GIOVANE; KRUGLIANSKAS, 2004).

Evidenciou-se uma abordagem oriunda da estratégia analítica, que não é adequada para empresas que atuam em cenário complexo, turbulento ou não linear (PETERS et al.).

Segundo a abordagem da empresa PE, a estratégia precisa ser mudada continuamente, uma vez que não há como prever o dia de amanhã.

Essa abordagem se enquadra na Teoria da complexidade, uma vez que a imprevisibilidade é devida à dependência sensitiva às condições iniciais (DSCI), segundo Freitas (2005) e Anselmo (2005). 
Em dez abordagens, somente uma não acredita em mudança contínua de estratégia. Anselmo (2005), Eisenhard e Schoonhoven (1990) advogam que, dentro da abordagem da complexidade, existe a necessidade de mudança de estratégia, a reinvenção constante da empresa.

Uma empresa sugere verificar se o resultado é bom o suficiente. Essa abordagem coincide com o referencial teórico "Eficiência em sistemas caóticos" (GIOVANE; KRUGLIANSKAS, 2004).

Pergunta 3: A estratégia da empresa é mudada continuamente com a finalidade de manter o equilíbrio dinâmico e evitar a bifurcação ou turbulência máxima?

Salienta-se que a empresa AC, por meio de seu dirigente, não acredita na necessidade de haver mudança constante, acrescentando que, se está trilhando um caminho e se encontra uma dificuldade, nesse momento é necessário mudar a estratégia, mas obrigatoriamente não se tem que mudar antes de ver o resultado. 0 que está acontecendo é que o pessoal está mudando para ter um resultado meIhor, sem saber se o resultado anterior está satisfatório (Sic). Está havendo um atropelo de metas (Sic).

Este comentário coincide com a eficiência em sistemas complexos e não lineares, uma vez que, para sobreviver, o sistema não precisa encontrar a melhor alternativa possível, basta que funcione (GIOVANE; KRUGLIANSKAS, 2004).

Evidenciou-se uma abordagem oriunda da estratégia analítica, que não é adequada para empresas que atuam em cenário complexo, turbulento ou não linear (PETERS et al.).

Segundo a abordagem da empresa PE, a estratégia precisa ser mudada continuamente, uma vez que não há como prever o dia de amanhã.

Essa abordagem se enquadra na Teoria da complexidade, uma vez que a imprevisibilidade é devida à dependência sensitiva às condições iniciais (DSCI), segundo Freitas (2005) e Anselmo (2005).

Em dez abordagens, somente uma não acredita em mudança contínua de estratégia. Anselmo (2005), Eisenhard e Schoonhoven (1990) advogam que, dentro da abordagem da complexidade, existe a necessidade de mudança de estratégia, a reinvenção constante da empresa.

Uma empresa sugere verificar se o resultado é bom o suficiente. Esta abordagem coincide com o referencial teórico "Eficiência em sistemas caóticos" (GIOVANE; KRUGLIANSKAS, 2004).

\section{CONCLUSÃO}

Os resultados finais deste trabalho atendem à problematização de existirem elementos típicos da Teoria da Complexidade na gestão de organizações que operam em ambiência turbulenta, dinâmica e não linear, e se a visão, missão e objetivos consistem atratores que evitam que a bifurcação ou que ponto de ruptura se instale. Atendendo também o objetivo geral de analisar a teoria da complexidade sob a perspectiva da gestão, além dos objetivos específicos de analisar os conceitos da Teoria da complexidade. 


\section{REFERÊNCIAS}

ANSELMO, Estevão. Modelo de gestão não linear: a Teoria do Caos e Complexidade aplicada à gestão de empresas de alto crescimento em ambientes dinâmicos e imprevisíveis. 2005. 155 f. Tese (Doutorado) - Departamento de Administração - Programa de Pós-graduação em Administração da Faculdade de Economia, Administração e Contabilidade da Universidade de São Paulo, São Paulo, 2005. Disponível em: <http://www.google.com.br/search?q=ANSELMO\%2C+Estev\%C3\%A3o\%3B+Mod elo+de+gest\%C3\%A3o+n\%C3\%A3o-linear\&rls=com.microsoft:en-us:IE-SearchBox\&ie=UTF-8\&oe=UTF8\&sourceid=ie7\&rlz=117RNTN_em>. Acesso em: 20 jan. 2013.

BERTALANFFY, Ludwig Von. Teoria geral dos sistemas. 2. ed. Petrópolis: Vozes, 2008.

BAUER, Ruben. Gestão da mudança: caos e complexidade nas organizações. São Paulo: Atlas, 2008.

BROWN, Shona L.; EISENHARDT, Katheen M. Estratégia competitiva no limiar do caos. São Paulo: Pensamento, 1998.

COLLIS, Jill; HUSSEY, Roger. Pesquisa em administração: um guia prático para alunos de graduação e pós-graduação. 2. ed. São Paulo: Bookman, 2005.

CKEIK, James. Chaos making a new science. 18. ed. New York: Penguin Group, 2008.

DAFT, Richard L.; LENGEL, Robert H. O desafio do caos. In: CUNHA, Miguel P. et al. (Org.). Empresas, caos e complexidade. Lisboa: $\mathrm{RH}, 2001$. Cap. 3.

EISENHARDT, Kathleen M.; SCHOONHOVEN, Claudia Bird. Organizational Growth: Linking Founding Team, Strategy. Environment and growth among. Administrative Science Quarterly, v. 35, Issue 3, p. 504-529, Sept. 1990. Disponível em: <http://web.ebscohost.com/ehost/pdfviewer/ pdfviewer? vid=2\&hid=119\&sid=fb4d7669-0a4f-4ca9-82ab- 1 adb1 $109146 b \% 40$ sessionmgr $110>$. Acesso em: 21 nov. 2013.

FREITAS, Wanderley Barbosa de. As teorias do caos e da complexidade na gestão estratégica. 2005. 148 f. Dissertação (Mestrado em Administração) - Universidade Municipal de São Caetano do Sul, São Caetano do Sul, 2005.

GIOVANNINI, Fabrício; KRUGLIANSKAS, Isak. Organização eficaz: como prosperar em um mundo complexo e caótico, usando um modelo de racional de gestão. São Paulo: Nobel, 2004.

GUO, Xitong; VOGEL, Doug; ZHOU, Zhongyun (Phil); ZHANG, Xi; CHEN, Huaping. Chaos Theory as a Lens for Interpreting Blogging. Journal of Management Information Systems, [S. I.], v. 26, Issue 1, p. 101 127, summer 2009. Disponível em: <http://web.ebscohost.com/ehost/pdfviewer/pdfviewer?vid=2\&hi $d=110 \&$ sid $=6 c 496 f 1 f-1 a 1 b-4418-$ be6b-c410a72d6efc\%40sessionmgr113>. Acesso em: 14 nov. 2013.

HITT, M. et al. Administração estratégica. 2. ed. São Paulo: Pioneira Thomson Learning, 2008.

HUNG, Shih-Chang; TU, Min-Fen. Is Chaos Theory Useful In Describing Technological Change? Academy of Management Proceedings, Chicago, p. 1-6, 2009. Disponível em: <http://web. ebscohost.com/ehost/pdfviewer/pdfviewer?vid=2\&hid=112\&sid=b6ba71 ee-3c90-49df-8ad8010b922a366f\%40sessionmgr114>. Acesso em: 14 nov. 2013. 
MARIOTTO, Fábio Luis. Mobilizando estratégias emergentes. Revista de Administração Empresarial, São Paulo, v. 43, n. 2, p. 78-93, abr./maio/jun. 2003.

MATOS, Jose Gilvanamar R.; MATOS, Rosa Maria B.; ALMEIDA, Josimar Ribeiro de. Análise do ambiente corporativo: do caos organizado ao planejamento estratégico das organizações. Rio de Janeiro: E-papers, 2007.

MINTZBERG, Henry. Ascensão e queda do planejamento estratégico. Porto Alegre: Bookman, 2004.

MORGAN, Gareth. Imagens da Organização. São Paulo: Atlas, 2009.

MORIN, Edgar; MOIGNE, Jean-Louis Le. A inteligência da complexidade: epistemologia e pragmática. 2. ed. Instituto Piaget: Lisboa, 2009.

MORIN, Edgar. Introdução ao pensamento complexo. 3. ed. Lisboa: Instituto Piaget, 2007.

NONAKA, I.; TAKEUCHI, H. Criação de conhecimento na empresa. 20. ed. Rio de Janeiro: Campus, 1997.

PARIKH, Jagdish; NEUBAUER, Friedrich; LANG, Alden G. Intuição: a nova fronteira da administração. 4. ed. São Paulo: Cultrix, 2003.

PETER, J. T.; HAMMOND, K. R.; SUMMER, D.A. A note on intuitive vs. analytic thinking. Organizational Behavior and Human Performance, [S. I.], v. 12, p. 125-131, 1974.

PRIGOGINE, llya. O fim das certezas: tempo, caos e as leis da natureza. São Paulo: Editora da Universidade Estadual Paulista, 1996.

RADOSAVLJEVIĆ, Milan; HORNER, R.; MALCOLM, W. The evidence of complex varia-ble-ity in construction labour productivity. Construction Management \& Economics, [S. I.], v. 20, Issue 1, p. 3-12, Jan. 2002. Disponível em: <http://web.ebscohost.com/ehost/pdfviewer/pdfviewer?vid=2\&hid=110\&sid=91 b637467bf7-4f46-8f8a-afa895894a55\%40sessionmgr110>. Acesso em: 21 nov. 2013.

SENGE, Peter M. A quinta disciplina. 24. ed. Rio de Janeiro: Best Seller, 2008.

TETENBAUM, Toby J. Shifting Paradigms: From Newton to Chaos, 1998. Organizational Dynamics, [S. I.], v. 26, Issue 4, p. 21-32, Spring 1998. Disponível em: <http://web.ebscohost.com/ehost/pdfviewer/ pdfviewer?vid=2\&hid=105\&sid=71733fa5-41d3-4df7-a841-32e26a2aaafe\%40sessionmgr1 12>. Acesso em: 20 nov. 2013.

THIETART, R. A.; FORGUES, B. Chaos Theory and Organization. Organization Science, [S. I.], v. 6, Issue 1, p.19-31. Jan./Feb. 1995. Disponível em: <http://web.ebscohost.com/ehost/pdfviewer/pdfviewer?vid=2\& hid=107\&sid=fbd8f0e2-bd8b-43ee-a709-21d5eeb0e072\%40sessionmgr110>. Acesso em: 14 nov. 2013.

WILBER, Ken. Uma teoria de tudo. 3. ed. São Paulo: Cultrix, 2007.

WHEATLEY, Margaret J.; ROGERS, Myron Lellner. Um caminho mais simples. 9. ed. São Paulo: Cultrix, 2000.

WHEATLEY, Margaret J. Liderança e a nova ciência: descobrindo a ordem num mundo caótico. 8. ed. São Paulo: Cultrix, 2006. 